\title{
Equilibrio en las finanzas públicas frente a las contingencias y demandas contra el Estado colombiano
}

\author{
A balance in public resources in the face of contingencies and lawsuits against \\ Colombian state
}

Recibido: 12/03/14 - Aprobado versión final: 02/09/14

Gleidy Alexandra Urrego Estrada*

\begin{abstract}
Resumen: en este artículo investigativo se identifican posibles acciones orientadas a equilibrar las finanzas públicas frente a las demandas interpuestas contra el Estado colombiano. La estrategia metodológica fue inductiva, partió de la revisión del Decreto 111 de 1996 y los informes de la Agencia de Defensa Patrimonial Estatal. Los principales resultados del artículo se enfocaron en salvaguardar el presupuesto público a través de un acercamiento al modelo de análisis multicriterio.
\end{abstract}

Palabras clave: demandas contra el Estado, finanzas públicas, defensa jurídica, Estado.

Abstract: this research paper identifies potential actions focused on balancing public finance to counteract lawsuits lodged against the State. The methodological strategy was an inductive one, based on the revision of Decree 111 of 1996 and reports by the Agency for the Defence of State Patrimony. The main findings of this paper were focused on safeguarding public budget by approaching a multicriteria analysis model.

Keywords: lawsuits, public finance, legal counselling, State.

JEL: H50, H61

* Administradora Pública y Magíster en Hábitat. Catedrática de la Universidad Nacional de Colombia e integrante del Grupo de investigación Observatorio Público del Tecnológico de Antioquia, Medellín - Colombia. gleidy.urrego@gmail.com 


\section{Contekto Urrego, G.}

\section{L'équilibre des finances publiques face aux aléas et aux plaintes à l'encontre de l'État colombien}

Résumé: cet article de recherche porte sur l'identification des possibles actions visant à l'équilibre des finances publiques face aux plaintes à l'encontre de l'État. La méthodologique a été inductive. On a commencé avec l'analyse du décret 111 de 1996 et des rapports de l'Agence de Défense du Patrimoine de l'État. Le but des principaux résultats de l'article a été de sauvegarder les finances publiques par le biais d'une approche selon l'analyse multicritère.

Mots clé: plaintes, finances publiques, défense juridique, État.

\section{Introducción}

La finalidad y la responsabilidad del actual Estado son antecedidas por la ciudadestado, como lo planteó Aristóteles a partir de la organización política de la urbe fuera de la esfera privada - el hogar y su administración doméstica -, para establecer praxis y discursos en asuntos humanos (Arendt, 2005). Esto es, establecer la articulación de poderes y la autoconciencia individual en la ciudad-estado como instrumento público para alcanzar la felicidad y los intereses de los ciudadanos. La pretensión no es, entonces, realizar una historiografía del surgimiento del Estado sino, más bien, dimensionarlo a partir de la producción conjunta de vivir en colectivo como individuos con intereses en común de bienestar y protección de su propiedad, y que depositan esta tarea en el Estado para preservarla como bien común.

El Estado aún interviene y garantiza bienestar a los ciudadanos, así se suscribió en el marco del pensamiento paternalista a partir de la segunda mitad del siglo XIX y principios del siglo XX, cuando después de la posguerra se evidenció un reordenamiento de la perspectiva competencial del Estado. Se resalta el equilibrio entre la burocratización y la politización de las instituciones gubernamentales, ambas se enfocaron en la centralización del poder y la legitimidad del aparato administrativo. Un Estado moderno, que es antecedido por el Estado egipcio-faraónico; el Estado de ciudades-estado, en la antigua Grecia, el Estado medieval, basado en la relación entre la Iglesia, los señores feudales y la monarquía como centro del poder; el Estado estamental o corporativo, como la unión de grupos sociales organizados, representados en asambleas institucionalizadas; el Estado premoderno, marcado por la doctrina de la soberanía de Jean Bodino (1529-1596); hasta llegar al Estado moderno que en el que, para Max Weber (1864-1920), el ejercicio del poder se da de forma racional, conforme a reglas que permiten tener un control.

1. Al Estado se le confiere el cumplimento de funciones que la ciudadanía demanda. 
Un Estado moderno que surge en Europa tras la demanda fundamental de constituciones en las cuales se expresen el ejercicio del poder, los derechos de los ciudadanos y la soberanía, especialmente estructural o funcional. El Estado moderno, según Benz (2010) es una mezcla decimonónica de conceptos: Estado como centro, el pueblo como individuos, la nación como una colectividad y la res-pública -la cosa pública-; estas a modo de ideas de fraternidad, lo cual dio lugar a un proceso de democratización y constitución de las competencias estatales conminadas a la función social y el proteccionismo societal, que es salvaguardar los derechos y la justicia social. Las competencias del Estado moderno son competencias evolutivas que van desde la reglamentación de la vida pública y privada a través de dispositivos policiales, hasta un Estado democrático de bienestar, en el cual predomina no la extensión territorial y la población, sino el capital y el conocimiento tecnológico.

En Hobbes, el Estado obedeció al carácter asociativo del hombre político, y su responsabilidad radicó en la naturaleza de esa sociedad política. De ahí que el Estado sume a sus competencias asuntos gubernamentales de administración de su aparataje burocrático, cuya exigencia incorpora la estructuración de asuntos fiscales en la capacidad técnica y la dirección eficiente. En el siglo XXI hay quienes consideran que las funciones centrales del Estado son las de garantizar justicia y seguridad, basados en que es el individuo el encargado de su bienestar. Al respecto Boaz considera que “[...] según los liberales, son los individuos los que tienen el derecho y la obligación de tomar sus propias decisiones". (2007, p. 431)

El Estado contemporáneo se orienta en la seguridad de la vida privada, basado en la legitimidad de su cumplimiento a la sociedad, un Estado sumergido entre el bienestar regulador y una reinvención pública, que en Colombia se evidencia entre un Estado garante de bienestar y de regularización. Un Estado que aún debe responder a los compromisos de intereses en común de sus gobernados y cuya intervención consiste no sólo en garantizar bienestar sino en ser responsable de sus actuaciones y del despliegue del aparato administrativo e instrumental, cuyas consecuencias positivas o negativas son consideradas en términos administrativos, pecuniarios y presupuestales.

Actualmente el Estado, especialmente el colombiano, fundamenta su naturaleza en la legitimidad institucional a través de la racionalidad de los recursos fiscales, el conocimiento técnico y la capacidad de coerción, a su vez, garantiza esa legitimidad ante el ciudadano a través de re-estructurar sus funciones y recursos económicos bajo principios eficientistas.

En esa medida, el presente artículo aborda al Estado a partir de su responsabilidad y el cumplimiento del cometido "garantizar a sus gobernados intereses en común de bienestar y protección de su propiedad". Asimismo, en el marco de responsabilidad estatal, analiza el papel y la importancia de la Agencia de Defensa Jurídica del Estado, si hablamos de evitar más demandas y llevar en buenos términos las actuales; $\mathrm{y}$ reflexiona sobre la afectación en el presupuesto público de las demandas contra el Estado y su resarcimiento económico. Además, se propone contemplar la 


\section{Contekto Urego, G.}

flexibilización de la programación presupuestal para el cubrimiento de las demandas, a través de la redefinición normativa de los fondos especiales, debido al fuerte impacto económico en las finanzas públicas.

\section{Metodología}

La estrategia metodológica tuvo como método el inductivo. Por una parte, se revisó el Decreto 111 de 1996 (Ley orgánica de presupuesto nacional) frente a la programación presupuestal, las cuentas del presupuesto público, su programación y ejecución, al igual que aquellas cuentas relacionadas con palabras claves como multas, sanciones y demandas, tanto de ingreso como de egreso. Por otra parte, se revisaron los informes de la Agencia de Defensa Jurídica del Estado que dieron cuenta de las estrategias y políticas relacionadas con el tema de defensa jurídica patrimonial del Estado, así como las leyes y artículos de prensa que tienen que ver con el tema y la Ley 672 de 2001: "Por medio de la cual se reglamenta la determinación de responsabilidad patrimonial de los agentes del Estado a través del ejercicio de la acción de repetición o de llamamiento en garantía con fines de repetición".

Igualmente se tuvo en cuenta la Ley 144 de 2011: "Por medio de la cual se escinden unos ministerios, se otorgan precisas facultades extraordinarias al presidente de la República para modificar la estructura de la administración pública y la planta de personal de la Fiscalía General de la Nación y se dictan otras disposiciones", comunicados de prensa y manuales en presupuesto del Ministerio de Hacienda y Crédito Público desde el 2008 hasta la fecha; rastreo de información de fuentes de prensa nacional como Revista Semana, El Colombiano, RCN Radio, entre otros.

Después de la revisión de las fuentes se prosiguió con el cruce de información contenida tanto en la Ley como en la prensa en relación con demandas en contra del Estado y su incidencia en la afectación presupuestal. Todo ello para realizar un acercamiento al modelo de análisis multicriterio, que agrupa varios juicios y criterios que den cuenta de la actual capacidad normativa en materia de presupuesto público.

\section{Resultados}

\section{La contabilidad pública como herramienta de control en el Estado}

Si bien la problémica que aborda el Estado es la composición de la sociedad en términos del control, se ha observado que desde el punto de vista 
sociológico, los dispositivos de $\operatorname{control}^{2}$ que se ejercen sobre la sociedad involucran directamente el quehacer contable en lo teórico, metodológico y técnico, puesto que el Estado y sus instituciones requieren herramientas para cumplir su función de trabajar por el bienestar de la población y la continuidad de las instituciones.

Los modelos de control que tradicionalmente ha contemplado la contabilidad, son aquellos que se despliegan de las teorías propias de la auditoría, desde el punto de vista del control anglosajón, y de la revisoría fiscal, a partir del control latino o continental europeo, lo cual ha permitido que la contabilidad se convierta en una herramienta fundamental en los ámbitos público y privado para el desarrollo de las organizaciones productivas a través de la revelación fidedigna de la realidad social.

El control organizacional debe permear las estructuras tanto públicas como privadas de los sectores productivos, puesto que se requiere generar custodia de los recursos que las organizaciones manejan para el desarrollo de sus objetos de realización organizacional. Es así que la contabilidad pública, como rama de la contabilidad (García-Casella, 2002), aporta elementos de análisis para el control y la defensa del patrimonio del Estado. En este marco de ideas, toma importancia el Decreto 111 de 1996, el trabajo en los campos de la disciplina contable, a través de la transdisciplinariedad, en aspectos que den cuenta de la realidad compleja y distante, y que se brinden herramientas que apunten a satisfacer las necesidades que la sociedad requiere, aquellas que se gritan y nadie parece escuchar.

Desde el punto de vista académico la contabilidad pública, más allá de un cúmulo de conocimientos técnicos, identifica y construye conocimientos teóricos y humanos; estos conocimientos no riñen entre sí, por el contrario, se acompañan en la búsqueda de cientificidad y rigurosidad investigativa, y a su vez están permeados por las demandas sociales que hacen los individuos a través de los grupos para la preservación de la vida privada en común. Es relevante llevar a cabo un estudio juicioso que dé cuenta de la injerencia de la sociedad en la construcción de herramientas contables que cuiden el patrimonio del Estado y comprendan la realidad organizacional pública. Lo que se pretende entonces, es evidenciar la importancia que registra la contabilidad pública en la discusión suscitada en este escrito de investigación, la cual no se aleja de la construcción del pensamiento, de la ciencia y de la sociedad, puesto que la contabilidad responde a las condiciones y necesidades requeridas a partir de los imaginarios de control fiscal que se construyen colectivamente.

2. Concepto del campo de la filosofía que desarrolló Paul-Michel Foucault (1926-1984) durante su historia académica, que se traduce como el conjunto heterogéneo de discursos, no discurso, instituciones reglamentaciones, leyes, entre otras, que exteriorizan las conductas y las formas de vida humanas bajo una sociedad estructurada. 


\section{Contekto Urego, G.}

La contabilidad pública tiene alta representatividad tanto en el contexto de lo público como en el estatal (Arendt, 2005), lo cual identifica una cuestión conceptual que requiere ser discutida profundamente cuando se implementan controles que relacionan finanzas y presupuesto público. Ahora bien, la contabilidad puede contribuir a la defensa del patrimonio del Estado, en tanto se definan acciones de responsabilidad social que redunden en beneficio de la transparencia, la generación de confianza pública, la rendición de cuentas a los entes de control y vigilancia, además de la sociedad en general, la actuación ética y responsable, el interés público, la gobernanza en sintonía con los nuevos estándares internacionales y nacionales de generación de información - financiera y no financiera -, entre otros asuntos que intervienen en la construcción de sociedad y de ciudadanía.

Contribuir a la defensa del Estado y a la transparencia de la información, en especial del presupuesto público, es un imperativo sociopolítico que se extiende a esferas técnicas, burocráticas, comunitarias y privadas que poco a poco deben articularse en acciones proteccionistas hacia las finanzas públicas, a la vez que éstas se deben reflejar en el bienestar común. En este sentido, el sistema nacional de contabilidad pública tiene la función social de aportar a la construcción de un Estado mucho más consecuente y humano con las necesidades de las inmensas mayorías; su accionar es imprescindible en la rendición de cuentas, esto es, el derecho a la información, como un elemento fundamental para la existencia de la transparencia.

\section{Hacia un equilibrio presupuestal frente a las demandas contra el Estado}

En el marco de las acciones que el Estado colombiano enfrenta en materia de demandas, el resarcimiento por responsabilidades que le competen dentro de sus funciones, la responsabilidad estatal se ha tornado en dos rutas: la primera el cumplimento social y constitucional de su deber y, la segunda, subsanar el daño o pena causados por su actuar, que en la mayoría de los casos guardan igual proporción. En un Estado que está bajo los vaivenes de las actuaciones de sus servidores públicos, las demandas se han transformado en factor de carga fiscal en el presupuesto ${ }^{3}$ y las finanzas públicas, ${ }^{4}$ además el crecimiento de las mismas resta credibilidad institucional ante los ciudadanos.

En Colombia se creó la Agencia de Defensa Jurídica del Estado, que a partir de la Ley 678 de 2001 encamina esfuerzos para la defensa del Estado, e insta a la reglamentación de la responsabilidad patrimonial que deben tener los servidores y exservidores públicos en el desempeño de sus funciones, a través de la acción de repetición, como consecuencia de su conducta. Esta conducta en la Ley se divide en conducta dolosa o gravemente culposa, siempre y cuando el Estado haya hecho reconocimiento indemnizatorio.

3. Alude al conjunto operativo de programación y ejecución del recurso económico.

4. Alude al conjunto de disposiciones funcionales en cuanto a la norma y el presupuesto en las entidades gubernamentales. 
El propósito de la Agencia de Defensa Jurídica del Estado, en la Ley 1444 de 2011, es fortalecer las herramientas jurídicas (Decreto 4585 y Decreto 4586 de 2011) que permitan equilibrar y valorar las demandas contra el Estado, el grado de actos cometidos por el mismo, a través de sus instituciones y servidores públicos, quienes, en carácter de persona o institución, sean los que respondan ante el llamado sancionatorio a que hubiera lugar, donde se esgrima su grado de responsabilidad. En esta Agencia se ve reflejado el interés del Estado por su defensa patrimonial que esencialmente es la sostenibilidad presupuestal y la inversión pública, pues es un problema acumulativo que requiere medidas para contrarrestar nuevas demandas contra el Estado, y sin una debida evaluación del grado de responsabilidad del mismo.

La Agencia debe garantizar que las actuales demandas contra el Estado se lleven en buenos términos. Una agencia que debe implícitamente reflexionar y promover las posibles causas que rodean la compleja actuación estatal, sobre todo en procesos contencioso-administrativos, frente a la multitud de querellas que se presentan contra el Estado. Como lo muestra la Figura 1, en las instituciones públicas de la rama judicial se presenta una congestión en los procesos judiciales, y en el área administrativa - competencias -, comportamientos ilegales por parte de sus servidores.

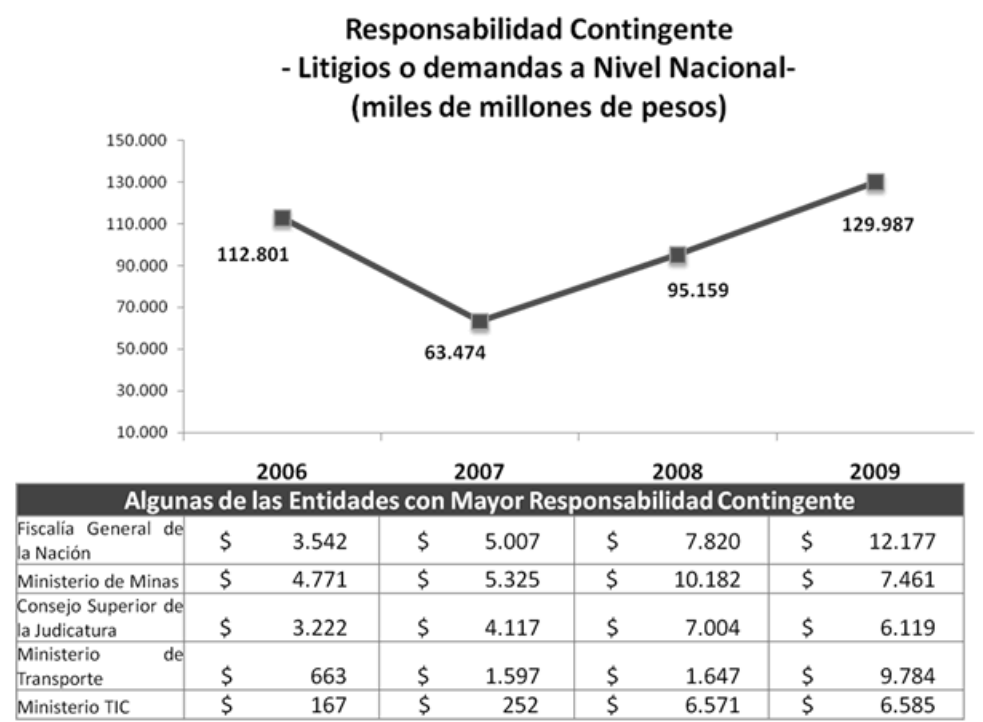

Figura 1. Demandas contra el Estado a nivel nacional

Fuente: tomado de Corporación Excelencia en la Justicia - CEJ -

(20 de diciembre, 2010). 


\section{Contekto Urego, G.}

Al respecto, la Agencia Nacional de Defensa Jurídica del Estado - ANDJseñala que

[...] el Sector Hacienda y Crédito Público lidera la lista con una participación de $22.8 \%$ del total de pretensiones en contra de la Nación. Este sector concentra el mayor valor de pretensiones para septiembre de 2013, las cuales ascienden a $\$ 67$ billones. En segundo lugar, el sector Defensa con un total de 139 procesos por encima de \$20 mil millones, y en tercer lugar la Fiscalía. En la actualidad existen 650 procesos de más de \$20.000 millones con unas pretensiones de $\$ 126.8$ billones que equivalen a $66 \%$ de las pretensiones en contra de la Nación. (2013, p. 12-13)

Las actuaciones del Estado están en una lógica de descrédito ante sus ciudadanos - deslegitimación de lo gubernamental -. La información de la Figura 1, aunque no reciente, presenta y consolida un panorama en relación con las demandas que enfrenta el Estado, las cuales en su mayoría son en la administración de justicia.

La responsabilidad estatal radica en el Artículo 90 de la Constitución Nacional, que exige la reparación de las actuaciones generadoras de daños o perjuicios a que hubiera lugar por parte del Estado. Este artículo constitucional se orienta esencialmente a la reparación del perjuicio una vez se presenta un daño antijurídico, el cual pudo originarse en una conducta ilícita como también en una conducta lícita del Estado. Las condenas las profiere la jurisdicción de lo contencioso administrativo, es decir, son los jueces quienes directamente entran a condenar las conductas estatales, sin intervención de la Agencia de Defensa Jurídica del Estado, y los pagos indemnizatorios tienen que ser respaldados en el erario público. A su vez, el Estado está en la potestad de demandar tanto a los servidores como a los exservidores públicos o a quien haya dado lugar al daño para el cubrimiento de la indemnización pagada al particular cuyo fallo fue a favor, y en cierta medida se pueda recuperar el daño presupuestal que ello implica.

Según Vega de Herrera (2014):

Las causas de tal situación no son atribuibles a los titulares de los derechos en discusión y menos a sus apoderados, que en ejercicio del derecho fundamental de petición aquellos, y para cumplir el requisito de representación judicial estos, acuden ante los jueces en la búsqueda de soluciones. Salvo casos excepcionales de fraude, incluidas las sentencias contrarias a derecho, en cada demanda está implícita, como su base, la presunción de una actividad del Estado generadora de perjuicios antijurídicos que, conforme al Artículo 90 de la Carta, exigen reparación. El empleo de mecanismos judiciales, lejos de ser una actividad indebida o ilegal para esquilmar al erario, se articula y guarda correspondencia con la estructura del Estado de Derecho y con los fines de éste en relación con la tutela y garantía de los derechos fundamentales. 
En tela de juicio están las actuaciones del Estado, por ende, la Agencia pretende que la gestión pública jurídicamente sea coherente con el mandato constitucional manifiesto en el Artículo 90 y con la etapa de resarcimiento a que hubiere lugar del daño causado por parte del Estado. Asimismo, se requiere la elaboración de políticas estatales en las cuales se considere: 1) Consolidar las demandas y la etapa de su proceso; 2) Establecer el riesgo jurídico, que consiste en la articulación con la Ley de reforma a la justicia; 3) Fortalecer la modernización y la profesionalización de la administración estatal, a partir de considerar que un puesto de trabajo sea por creación o supresión, esté de conformidad con el manual de funciones y un estudio de carga de trabajo.

El enfoque de buen gobierno que pretende el Estado colombiano, esto es, el direccionamiento de metas concretas, la gestión por resultados, la definición de acciones y la capacidad institucional para lograrlas, tiene que ver con la transformación de la administración pública, en materia de eficiencia y eficacia en cada una de sus actuaciones, donde la municipalidad debe garantizar el desarrollo territorial local. En esa medida, a una escala espacial-territorial, las competencias del gobierno nacional-local radican en un modelo interinstitucional y de gerencia, en el cual la Agencia (ver Figura 2) tenga un sistema de información sobre los litigios que se adelanten para poder hacerles un seguimiento, y de este modo detectar cuáles son las fallas del Estado en el cumplimiento de sus funciones y cómo es el proceso de resarcimiento del daño causado.
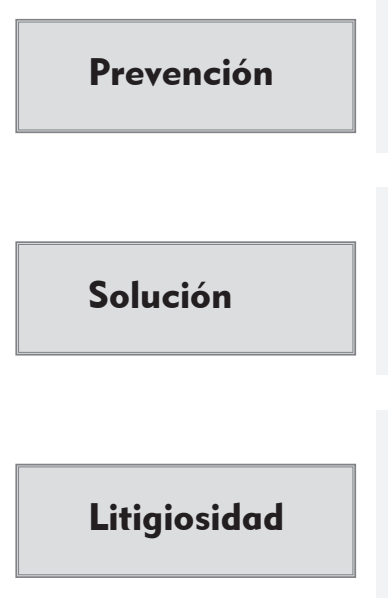

- Disminuir el número de condenas.

- Disminuir el impacto fiscal asociado.

Figura 2. Proceso de la Agencia para la Defensa Jurídica del Estado

Fuente: Veleño (2012). 


\title{
Contekto Urego, G.
}

En la excesiva litigiosidad contra el Estado, convendría que la Agencia se afiance en el principio de control interinstitucional, a través de las oficinas de control interno de las entidades públicas donde se presentan más querellas, para realizar un diagnóstico a posteriori, en el cual se identifiquen comportamientos y actuaciones repetitivas generadoras de demandas. Asimismo, las querellas se presentan internamente en las entidades públicas, sobre todo en relación con el empleo, por eso las políticas del Estado, en el marco de la nueva gestión pública, deben incluir como pilar la sostenibilidad de directrices en materia de bienestar otorgado a sus servidores, bajo el criterio de tiempo de permanencia en la institución, y así se disminuyan las demandas laborales.

Según la Agencia Nacional de Defensa Jurídica las demandas relacionadas con los procesos internos estatales, restablecimiento de derechos, asuntos laborales y asuntos de reparación directa, a 2012 ascienden al $21 \%$ de los procesos que adelantan (ver Figura 3). Con una agencia cuya misión es la estimación del daño patrimonial, debe incluirse como parte de su labor la clarificación jurídica y de competencia de las acciones directas e indirectas de quienes actúan en nombre del Estado. Una agencia en pro de la defensa jurídica pública, que concilia y concerta los litigios entre el Estado y las altas cortes.

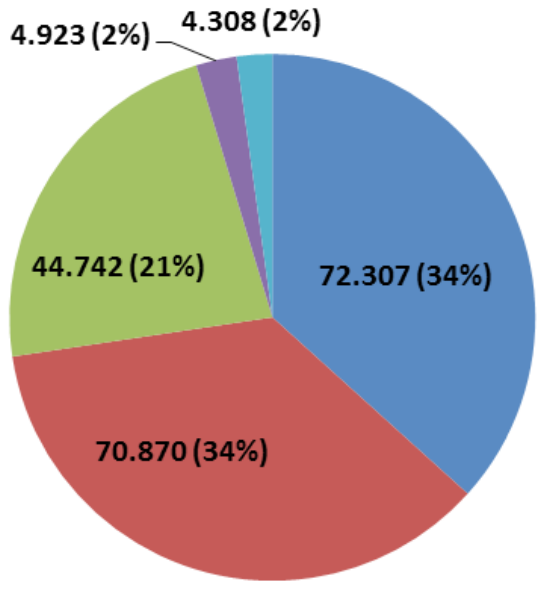

\author{
- ORDINARIO LABORAL \\ - NULIDADY \\ RESTABLECIMIENTO DE \\ DERECHO \\ REPARACIÓN DIRECTA
}

- ACCIÓN POPULAR

- EJECUTIVO LABORAL

Figura 3. Valor y porcentaje de procesos y acciones judiciales. Cifras en millones de pesos

Fuente: elaboración propia con base en Veleño (2012). 


\section{Las demandas contra el Estado y su afectación en el presupuesto público}

La carga que el Estado tiene con las demandas y el resarcimiento de daños ocasionados por sus actuaciones está en el presupuesto público, ya que la mayoría de demandas, como lo muestra la Figura 3, son en términos económicos. Por tanto, las finanzas públicas tienden a dividirse no sólo en la inversión pública reglamentada en el Decreto 111 de 1996 sino en contingencias difíciles de prever presupuestalmente, y con baja factibilidad de programar; porque la cuantía se desconoce y varía con relación al número de demandas presentadas y al monto de resarcimiento.

$\mathrm{Al}$ respecto, en la Revista Semana (30 de enero de 2012, p. 20) se lee lo siguiente:

Las cifras son aterradoras. En juego hay 1.028.000.000.000.000 de pesos. Esto equivaldría a unos 500.000 millones de dólares. Esta cifra corresponde a más de dos veces el Producto Interno Bruto de Colombia, que es de 50 billones de pesos al año. En términos de reformas tributarias significaría 100 veces la proyectada este año. Esta plata alcanzaría para construir 33 millones de casas de interés social, 54.000.000 jardines infantiles o para financiar la educación básica y universitaria a más de 55 millones de estudiantes. En otras palabras, si las 260.000 demandas que hoy cursan contra la nación prosperan, cada colombiano tendrá que pagar, hipotéticamente, 22 millones de pesos. ¿Cómo se ha llegado a este absurdo? La respuesta sencilla estaría en las imperfecciones del Estado, que llevaron a que se generara una carrera, en la que demandar a un Estado que es pésimo defendiéndose, sea el mejor negocio.

Un Estado que en la actualidad tiene 260.000 demandas, las cuales si prosperan incidirían en una baja inversión social cuyo monto presupuestal asciende a los 39 billones de pesos, según la directora de la Agencia Nacional de Defensa Jurídica del Estado, Adriana Guillén (RCN Radio, 2012). En la programación presupuestal del Estado para el año 2013, el Gobierno nacional radicó en el Congreso el Presupuesto General de la Nación para ese año, un presupuesto por $\$ 185,5$ billones, de los cuales la inversión alcanza $\$ 40,7$ billones y se destinan $\$ 6,2$ billones para la atención de las víctimas de la violencia, y el total de gasto social asciende al $70 \%$ del presupuesto, cumpliendo con lo ordenado por la Corte Constitucional. (Ministerio de Hacienda y DNP, 2013)

En materia de demanda, su resarcimiento no se estima presupuestalmente (montos económicos de las demandas y su afectación en las cuentas nacionales), lo cual hace difícil realizar un cuadro comparativo entre las demandas actuales y su valor financiero, frente a la actual programación presupuestal en el ámbito nacional. La información contable de las demandas, su monto, el cargo a un rubro presupuestal y su resarcimiento en las finanzas públicas no se cruzan, sino que se profundizan a medida que se cargan a cuentas estatales de pasivos contingentes, sin tener una programación en el presupuesto nacional. Por tanto, el fisco nacional 


\section{Contekto Urrego, G.}

siempre se verá comprometido frente al actuar del Estado en relación con la estabilidad jurídica, que debe estar subordinada a la estabilidad presupuestal.

Al respecto, la Agencia Nacional de Defensa Jurídica del Estado - ANDJ(2013, p. 8) señala:

Por otra parte, en términos de apropiaciones el comportamiento es muy similar y consecuente con el de pagos, a excepción del año 2009 en el que aumentó un 72\%, muy por encima del rango de incrementos históricos que osciló entre el 1,7\% y el 39,6\%. En el año 2012 la apropiación inicial fue de $\$ 938.302$ millones de pesos, y se adicionó en 30,3\% de manera que para el fin de año alcanzó la suma de \$1,34 billones. De esta partida se ejecutaron pagos del $88,5 \%$, es decir $\$ 1,19$ billones. Un monto cerca de cuatro veces el valor total pagado en el 2006 y alrededor de seis veces el valor total pagado en el 2000. (...) Frente a las adiciones presupuestales estas reflejan los problemas de planeación de las entidades, lo cual dificulta las proyecciones de las finanzas públicas en el corto y mediano plazo. Entre el 2000 y el 2011 las adiciones se mantuvieron relativamente bajas, pero durante el año 2012 se evidenció un incremento significativo de 30,2\%. Durante el año en curso las adiciones estaban, a septiembre, por el orden de \$125.129 millones (13\% de apropiación inicial) alcanzando \$1,07 billones.

En la clasificación y descripción de las cuentas que se manejan del Decreto 111 de 1996 no se puntualiza un plan de cuentas de los pasivos contingentes que permita dar soporte para atender presupuestalmente las demandas. De ahí que el Estado requiera una estructura financiera para atenderlas, que implique: 1) Redefinición de clasificaciones presupuestales, en los componentes de rentas y recursos de capital; y financiamiento, como fuentes y gastos e inversiones de capital (Ministerio de Hacienda, 2008). 2) Aspectos conceptuales y normativos para la clasificación presupuestal. Y, 3) Unificar criterios en materia de definiciones conceptuales, que clasifiquen las fuentes de financiación de las demandas.

Las demandas requieren financiación, en términos de programación presupuestal, a través de la redefinición normativa de los fondos especiales, que actualmente son un "ingreso permanente pero no de libre disposición como son las Rentas Parafiscales, [y] son catalogados como ingresos con destinación específica" (Ministerio de Hacienda, 2008), por tanto, serían dos panoramas normativos posibles. El primero es el aumento de la carga impositiva que engrose la cuenta, como son las rentas y los recursos del capital, decisión que no fue considerada en la nueva ley tributaria. (Ley 1607 de 2012)

El segundo es la flexibilidad de los fondos especiales a partir de normas que consideren aspectos puntuales como la subcuenta de multas, sanciones pecuniarias y depósitos en caución transferidos, lo cual es un ingreso no tributario que guarda relación con los tribunales o los órganos judiciales, y que se origina en el incumplimiento de las leyes o nomas administrativas. 
Por tanto, la Agencia de Defensa Jurídica del Estado, como parte de sus políticas de disminución del riesgo de demandas, deberá ponderar la relación jurídico-económica de las demandas generadas por el actuar de las instituciones de justicia (ver Figura 1) y los ingresos en esta subcuenta (Fondos Especiales).

El Ministerio de Hacienda y Crédito Público afirma:

Las multas y sanciones que conforman esta subcuenta incluyen las referentes al incumplimiento tributario de un impuesto determinado por parte de un contribuyente. En aquellos casos en que no sea posible identificar este tipo de multas y sanciones con el impuesto especifico al que corresponden, estas se incluyen en la subcuenta otros impuestos de los ingresos tributarios. (2008, p. 25)

Con el fin de dar otra destinación a los recursos (multas y sanciones) que ingresan a esta cuenta es necesario consolidar las actuales fuentes de financiación con que cuenta el Estado para resarcir las demandas, debido a que estas no tienen una programación presupuestal sólida dentro de las finanzas públicas nacionales para solventarlas. Esto permite sustentar que es inviable la financiación actual de las demandas a través de los ingresos de libre destinación, y que por tanto requieren un tratamiento especial de una subcuenta (ver Figura 4) de corto tiempo, pues, con la naturaleza de la Agencia Jurídica del Estado, debe verse reflejada en gestión, en términos de sostenibilidad presupuestal en las finanzas públicas; es decir, el Gobierno nacional debe mantener en el tiempo la administración del presupuesto programado y su ejecución, y reducir el número de demandas que se instauren contra el Estado.

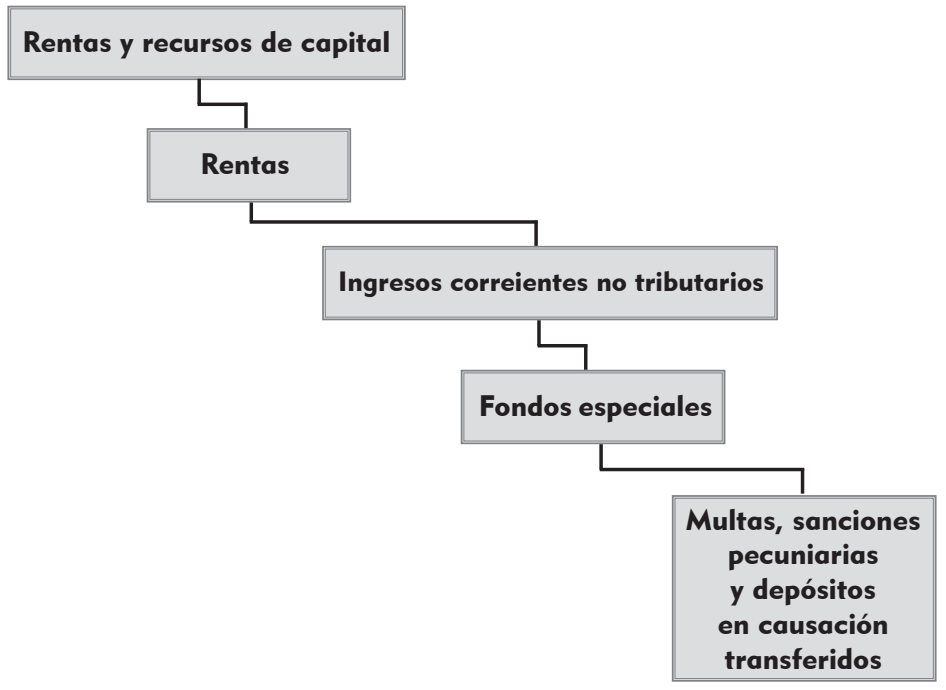

Figura 4. Categorías de la clasificación económica en presupuesto público

Fuente: elaboración propia con base en el Decreto 111 de 1996. 


\section{Contekto Urego, G.}

El Estado colombiano enfrenta un reto fiscal en materia de resarcimiento de las actuales y futuras demandas, lo cual requiere un análisis concreto de intervención que oriente hacia acciones que salvaguarden las finanzas públicas. Acciones que se canalicen bajo un modelo de análisis multicriterio, es decir, la agrupación de juicios, acciones y criterios que den cuenta de la actual capacidad normativa y presupuestal, y que confluyan hacia la valoración de alternativas por parte del Gobierno nacional. En este modelo multicriterio se puede identificar una lógica de intervención estatal, que radica en el control de demandas y en la defensa del presupuesto público a través de la Agencia para la Defensa Jurídica del Estado como máximo órgano de regulación pecuniaria contra el Estado.

Un modelo en el que se identifique un marco lógico de intervención de escenarios en los ámbitos nacional y local, con criterios como el principio de sostenibilidad presupuestal (expresado en el Decreto 111 de 1996) y la eficiencia fiscal, esto es, la distribución normativa de cargas presupuestales conforme a capacidades fiscales nacionales. Además, las acciones deben concentrarse en los pasivos contingentes o los fondos especiales, cuyos juicios de análisis sean a partir de lo dispuesto en el Decreto 111 de 1996: programación y ejecución presupuestal, y lo dispuesto normativamente en materia de modernización del Estado, relacionado con las competencias en el empleo público.

En la Figura 5 se perfila un cuadro multicriterio que corresponde a la presentación de un panorama de decisión en el quehacer estatal, un acercamiento a un modelo gerencial público para afrontar las demandas contra el Estado y resarcir el daño a que hubiere lugar. Es un cuadro multicriterio flexible que posibilita evaluar criterios y juicios de índole financiero-administrativa ex-antes y ex-post a la ejecución presupuestal nacional y, a su vez, la cohesión con los principios planificadores de concurrencia y ordenación de competencias que estipula la Ley 152 de 1994.

La gerencia pública según Rhodes (1996, p. 652-653), alude al buen gobierno, al afirmar que "el buen gobierno significa un cambio de sentido del gobierno, que permite a un nuevo proceso de gobernación, o bien al cambio experimentado por el mando ordenado, o bien al nuevo método conforme al cual se gobierna la sociedad". 


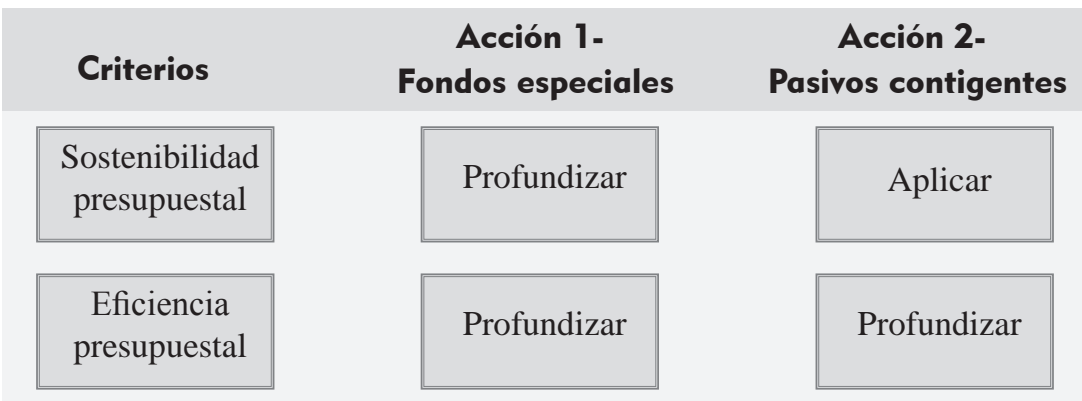

Figura 5. Propuesta de perfilamiento del análisis multicriterio para la defensa patrimonial en materia presupuestal

Fuente: construcción propia.

De acuerdo con la Figura 5, para la acción de los fondos especiales, profundizar hace alusión a una flexibilización normativa en la programación presupuestal, y especialmente en esta cuenta, alude a la posibilidad de engrosarla con otras cuentas estipuladas en el Decreto 111 de 1996 a través de la cuenta "rentas y recursos de capital" (ver Figura 4). Asimismo, la profundización que le sigue hace alusión a la identificación del estado de esta cuenta, cómo se programa, cómo se ejecuta, y que en el ámbito administrativo se tomen acciones en el debido cobrar, ya que guarda relación con las multas, sanciones pecuniarias y depósitos en causación. Frente a la acción dos, pasivos contingentes, aplicar hace alusión a un cambio normativo, que se priorice esta cuenta en la programación del presupuesto nacional y tenga destinación específica para contingencias del Estado en materia de demandas.

Asimismo, en la acción dos, "profundizar" hace alusión a identificar el estado de esta cuenta, cómo se programa y se ejecuta y que, a su vez, administrativamente se tomen acciones que la engrosen presupuestalmente a través de un porcentaje de participación no menor del $20 \%$ de la cuenta "pasivos contingentes", pero de las subcuentas: Fondo de Defensa y Fondos Internos Ministerio de Defensa. Más aún, el Gobierno nacional puede, por medio del artículo 111 del Decreto 111 de 1996, constituir una cuenta especial para atender el pago de la deuda externa del sector público.

Esto es, que el Gobierno nacional asuma como deuda pública el resarcimiento de las demandas contra el Estado. Sin embargo, esta postura implica mediaciones políticas antes que presupuestarias, en especial pasaría de ser un asunto de administración de fondos con el Fondo de Monedas Extranjeras del Banco de la República o mediante contrato directo, para convertirse en un asunto fiscal, manifiesto en la creación de un fondo especial 


\section{Contekto Urego, G.}

para la deuda pública con destinación presupuestal que se alimente de los "Recursos de capital de la nación" en la subcuenta de "Reintegros y Otros recursos no apropiados".

\section{Conclusiones}

La contabilidad pública se incorpora como herramienta en materia de control fiscal y en especial en el resarcimiento de las demandas contra el Estado. La contabilidad despliega instrumentos ex-antes, es decir, un control preventivo a través de la integralidad en las cuentas del presupuesto de orden nacional y, un post a través de la exactitud en la ejecución presupuestal. Si bien las demandas afectan el presupuesto público, es necesario que la contabilidad, como herramienta por excelencia aprobatoria, facilite el proceso de planificación, cálculo y evaluación del presupuesto público programado, al tiempo que permite la disponibilidad de información relevante que posee el Gobierno nacional para presentar informes y estados contables de las cuentas de que trata el Decreto 111 de 1996.

La contabilidad como herramienta de control fiscal debe sumarse a la misión y visión de la Agencia de Defensa Jurídica del Estado; esta Agencia debe articularse a los pilares de la gerencia pública del Estado moderno, es decir, eficacia, transparencia y eficiencia. La Agencia es una institución de formación jurídica, y en especial de formación técnica, en cuanto debe instruir y controlar el hacer público gubernamental bajo un enfoque de protección del Estado. De igual modo, desde la Agencia, la promoción de la legitimidad del Estado se hace necesaria en la medida en que se reestructure y articule normativamente como responsabilidad personal (a nombre propio - servidor público) cualquier actuación en cumplimiento de funciones públicas y que diera lugar a detrimento patrimonial en contra del Estado, y que al mismo tiempo la Agencia articule su actuación de control con las oficinas de control interno del orden territorial.

La Figura 5 presentó criterios y acciones loables en materia presupuestal, su elección depende de las altas esferas gubernamentales, y que estas se encaminen a profundizar o aplicar dichos criterios y acciones. Lo primero es la intervención y el control institucionales del Gobierno nacional en la administración y disminución de las demandas contra el Estado, y la flexibilización normativa en materia de presupuesto público para resarcirlas. Esto último se debe planificar en la programación y ejecución presupuestal de orden nacional para respaldar fiscalmente las demandas. Lo segundo es un cambio normativo funcional en la programación presupuestal, para establecer una cuenta especial de orden nacional, y así, con destinación específica se mitigue el daño económico que pudiera enfrentar el Estado. 


\section{Referencias bibliográficas}

Arendt, H. (2005). La condición humana. Barcelona: Paidós Surcos.

Benz, A. (2010). El Estado moderno. Fundamentos de su análisis politológico. Madrid: Centro de estudios políticos y constitucionales.

Bodin, J. (2006). Los seis libros de la República. Madrid: Tecnos.

Colombia, Agencia Nacional de Defensa Jurídica del Estado - ANDJE (2013). Informe sobre la actividad litigiosa de la Nación (fecha de corte: septiembre de 2013). Bogotá: Imprenta Nacional de Colombia.

Colombia, Congreso de la República. Ley 678 de 2001. Diario Oficial, 44.509.

Colombia, Congreso de la República. Ley 1444 de 2011. Diario Oficial, 48.059.

Colombia, Ministerio de Hacienda y Crédito Público (2008). Manual de clasificación económica del presupuesto. Bogotá: Documento DGPPN.

Colombia, Ministerio de Hacienda y Crédito Público, Departamento Nacional de Planeación - DNP - (2013). Comunicado de prensa N. ${ }^{\circ} 28$. Presupuesto General de la Nación 2013: Hacia un desempeño eficaz del Estado. Recuperado de http://www.minhacienda.gov.co/portal/pls/portal/ docs/1/5886730.PDF

Colombia, Presidencia de la República. Decreto 111 de 1996. Diario Oficial, 42.692.

Colombia, Presidencia de la República. Decreto 4085 de 2011. Diario Oficial, 48.240.

Colombia, Presidencia de la República de Colombia. Decreto 4086 de 2011. Diario Oficial, 48.240.

Corporación Excelencia en la Justicia - CEJ -. (2010, 20 de diciembre). Costo de las demandas contra el Estado colombiano. Recuperado de: http://www.cej.org.co/index.php/todos-los-justiciometros/2553-costode-las-demandas-contra-el-estado-colombiano

Foucault, M. (1997). Vigilar y castigar: nacimiento de la prisión. (26a . ed.) México: Siglo XXI.

García-Casella, C. (2002). El problema del uso de modelos en la contabilidad. Revista internacional de Contabilidad y Auditoría, 12, 199-235.

Hobbes, T. (2005). Del ciudadano y Leviatán. Madrid: Tecnos. 


\section{Contekto Urego, G.}

RCN La radio. (2012, 4 de diciembre). Demandas contra el Estado estarían entre 29 y 39 billones de pesos. Recuperado de http://www.rcnradio. com/noticias/demandas-contra-el-estado-estarian-entre-29-y-39billones-de-pesos-36667

Revista Semana. (2012, 30 de enero) 1.000 billones de pesos es la cifra que deberá pagar el Estado si prosperan las demandas en su contra. 1552 , p. $20-24$.

Rhodes, R. (1996). The New Governance: Governing without Government. Political Studies, 44, 652-667.

Vega, M. (2014, 4 de mayo). La Agencia Nacional de Defensa Jurídica y la guarda del patrimonio público [en línea]. ambitojuridico. com. Recuperado de: http://www.ambitojuridico.com/ BancoConocimiento/N/noti-120504-06_\%28la_agencia_nacional de_defensa_juridica_y_la_guarda_del_patrimonio_publico\% $29 /$ noti-120504-06_\%281a_agencia_nacional_de_defensa_juridica_y_ la_guarda_del_patrimonio_publico\%29.asp?Miga=1

Veleño, M. (2012, 24-25 de agosto). Presentación de la Agencia Nacional de Defensa Jurídica del Estado, en el marco de la "Semana de la defensa de lo público". Cali: Alcaldía de Santiago de Cali. Recuperado de www.cali.gov.co/descargar.php?id=32367

Weber, M. (2008). Escritos políticos. Madrid: Alianza Editorial.

\section{Para citar este artículo:}

Urrego, G. (2014). Equilibrio en las finanzas públicas frente a las contingencias y demandas contrael Estado colombiano. En-Contexto, 2,51-68. 